\title{
Pro-inflammatory cytokines and microRNAs in male infertility
}

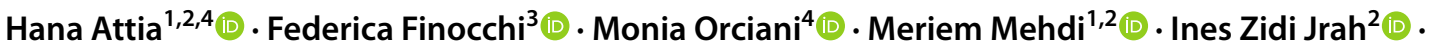

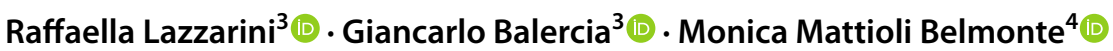

Received: 23 May 2021 / Accepted: 23 July 2021 / Published online: 28 July 2021

(c) The Author(s) 2021

\begin{abstract}
Background Male infertility is a problem that affects $10-15 \%$ of men of reproductive age. In particular, gametogenesis is a complex process in which inflammation may play a central role through the secretion of cytokines and the expression of microRNAs. We assessed the potential role of proinflammatory cytokines (TNF- $\alpha$, IL- 6 and IL- $1 \alpha$ ) and microRNAs (miR-146a-5p, miR-34a-5p and miR-23a-3p) in the seminal plasma of infertile men compared to controls, evaluating their correlation with seminal and biochemical parameters.

Methods and results Expression of cytokines and microRNAs was analyzed by ELISA and q-PCR. Our data shows that IL-1 $\alpha$ was significantly increased in the azoospermic group compared to controls, TNF- $\alpha$ mRNA was more expressed in the oligozoospermic group than controls. There were no significant differences in miRNAs expression among the three groups. The correlations between sperm parameters and inflammatory markers were evaluated, however no significance was highlighted. Conclusions The determination of each inflammatory marker separately in the seminal plasma of subfertile men, despite some significant differences, does not have a diagnostic value in male infertility even if an assay of selective pro-inflammatory cytokines and microRNAs in the semen may improve the diagnosis of male infertility.
\end{abstract}

Keywords Male infertility $\cdot$ TNF- $\alpha \cdot$ IL- $6 \cdot$ IL- $1 \alpha \cdot$ MicroRNAs

\section{Introduction}

Spermatogenesis is a very complex, highly organized process and its disruption may lead to male infertility. The achievement of male fertility requires the integration,

Hana Attia and Federica Finocchi have contributed equally to this manuscript.

Monia Orciani

m.orciani@staff.univpm.it

1 Department of Histology Embryology and Cytogenetic, Faculty of Medicine, University of Monastir, Monastir, Tunisia

2 Laboratory of Cytogenetics and Reproductive Biology, Center of Maternity and Neonatology, Fattouma Bourguiba University Teaching Hospital, Monastir, Tunisia

3 Division of Endocrinology, Department of Clinical and Molecular Science (DISCLIMO), Polytechnic University of Marche, Ancona, Italy

4 Laboratory of Histology, Department of Clinical and Molecular Science, Polytechnic University of Marche, Ancona, Italy communication, and functionality of distinct cell types in the testis throughout germ cell maturation [1]. Moreover, it is tightly controlled by cytokines [2] and their level has been found dysregulated in the seminal plasma of men with hypo-fertility [2]. Among the others, TNF- $\alpha$ is a crucial molecule that stimulates sperm peroxidation by the rise of reactive oxygen species (ROS) generation and apoptosis processes [3]. Cytokines are released by different immune cells in the male genital tract, such as macrophages, monocytes, lymphocytes, dendritic cells, and also as a reaction to foreign antigens and pathogens within chronic inflammation [4]. Several cytokines, including IL- $1 \alpha$, IL-6, TNF- $\alpha$, and activin A, are produced in a cyclical way by the Sertoli or spermatogenic cells during the maturation cycles of the seminiferous epithelium, implying that their actions are crucial to controlling this basic aspect of testicular functions [5]. Furthermore, it has been establish that exposing spermatozoa to elevated concentrations of TNF- $\alpha$ arise in a significant loss of their genomic integrity and functionality $[6,7]$. The relationship between pro-inflammatory cytokines, including IL- $1 \alpha$ and IL-6, and semen quality, is still debated. Some authors found a link between ILs and sperm motility/ 
ova-penetrating ability of spermatozoa [8], others reported no significant differences in ILs [9], potentially as a result of different population characteristics and assay methods.

Besides cytokines, other molecules have an important role in male infertility [10]. Khawar et al. reported as the aberrant expression of miRNAs influent spermatogenesis at numerous phases and in different cell types, frequently resulting in infertility [11]. Above all, the function of some miRNAs seems to be essential for male fertility. The expression of miR-146a-5p is finely regulated during spermatogenesis: it is strongly expressed in undifferentiated spermatogonia whereas its transcription is strongly decreased in differentiating spermatogonia [12]. The miR-23 family (miR-23a, b, and c) is strongly reduced in nemaspermic cell and seminal plasma exosomes of subfertile vs. fertile men. The miR-23 family regulates some spermatogenesis-specific genes such as PFKFB4, HMMR and SPATA6 [13]. Studies have shown that semen parameters (sperm count, motility and morphology) negatively correlated with the expression of the miR-23 family, while they positively correlated with reduced expression of the mentioned genes. Hence, a role of the miR-23 family in the pathogenesis of male infertility is hypothesized [13, 14].

In the current study, we aimed to evaluate the gene expression levels of pro-inflammatory cytokines (IL-6, TNF- $\alpha$ ) and miRNAs (miR-146a-5p, miR-34a-5p and miR$23 a-5 p)$ and the protein expression of IL-1 $\alpha$ both in infertile patients and controls, to clarify their interdependent relationship and their role in the etiopathology of male infertility.

\section{Materials and methods}

\section{Study population and sample collection}

We selected 45 patients who were referred to the Fattouma Bourguiba University Teaching Hospital of Monastir's fertility clinic. The study included 15 azoospermic patients, 15 oligozoospermic patients and 15 healthy normozoospermic men as controls. Blood and sperm samples were taken from each patient. The study was approved by Fattouma Bourguiba University Teaching Hospital of Monastir ethics committee, all patients had given their consent to participate in the study.

All patients included in the study had undergone the analysis during routine andrological screening. Exclusion criteria were endocrine disorders, urogenital tract infections, cryptorchidism, testicular cancer, or previous chemo/ radiotherapy.

All patients had a typical karyotype, and five of the oligozoospermic patients had a varicocele. Furthermore, there was no presence of $\mathrm{Y}$ chromosome microdeletions, obstructions, or genetic causes for all azoospermic patients (e.g. Klinefelter).

The semen examination was carried out according to WHO 2010 guidelines [15] and viability was also assessed by Eosin Y. In cases of azoospermia, the diagnosis was confirmed on a second semen sample.

To evaluate sperm morphology the seminal samples were stained by the kit spermoscan (Fast staining kit for spermocytograms, Martillac-France).

To provide a distribution of morphological abnormalities, morphological assessment according to the updated David classification was also performed [16].

Seminal plasma was obtained by centrifuging the sample at $13,000 \mathrm{rpm}$ for $15 \mathrm{~min}$ and frozen at $-20{ }^{\circ} \mathrm{C}$ for subsequent analyzes.

\section{Hormonal and metabolic analysis}

A peripheral blood sample was taken from each patient in the morning after overnight fasting. Serum levels of folliclestimulating hormone (FSH), luteinizing hormone (LH), prolactine and estrogen hormones were measured by Radioimmunoassay. In our laboratory, normal ranges for adults were $10 \mathrm{mU} / \mathrm{mL}$ (FSH), $1.1-10 \mathrm{mU} / \mathrm{mL}$ (LH), and 50-250 pmol/L (prolactine) and $20 \mathrm{ng} / \mathrm{mL}$ (estrogen). We also evaluated the lipic profile of the patients through triglycerides, (TG; normal value $<1.8 \mathrm{mmol} / \mathrm{L})$ and total cholesterol $(\mathrm{CH}$; normal value $<5.2 \mathrm{mmol} / \mathrm{L}$ ).

\section{ELISA}

IL- $1 \alpha$ concentration was determined with ELISArray kit (Biorbyt, Cambridge, United Kingdom) and the results were expressed in picograms per milliliter in accordance with the manufacturer's instructions.

\section{RNA extraction}

Total RNA was extracted from $300 \mu$ of the seminal plasma with Complete RNA Purification Kit (Norgen Biotek Company, Thorold, ON, Canada) according to the manufacturer's instructions. The RNA was kept at $-80{ }^{\circ} \mathrm{C}$ until it was used.

\section{Quantitative RT-PCR miRNAs}

MiRNAs were quantified using TaqMan MicroRNA Assay hsa-miR-146a-5p, hsa-miR-34a-5p and hsa-miR-23a-5p, with the endogenous control U6 snRNA for the seminal plasma (Thermo Fisher, Milan, Italy) as previously described [17-19].

Fluorescence data were converted to cycle threshold $(\mathrm{Ct})$ by ExpressionSuite v1.0.4 (Applied Biosystems) and the 
quantity for each target miRNA was calculated by the $\Delta \mathrm{Ct}$ method normalized on the basis of the U6 snRNA. Undetermined values were considered as equal to the maximum number of cycles, namely 35 .

\section{Expression of IL- 6 and TNF- $a$ by real-time PCR}

Real-time PCR was carried out using an Eppendorf Master Cycle (Hamburg, Germany) instrument and EVA Green PCR Master Mix (Bio-Rad, Milan, Italy) according to the manufacturer's instructions. At the end of the amplification process, a melting stage was added. There was no nonspecific amplification as determined by the melting curve. All samples were tested in triplicate and $\beta$-actin was used as reference genes for data normalization for TNF- $\alpha$ and IL-6. The quantity for each target mRNA was calculated by the $\Delta \mathrm{Ct}$ method normalized on the basis of the $\beta$-actin and RPL30. The primer sequences were as follows:

- TNF- $\alpha$ for: 5'-GGTGCTTGTTCCTCAGCCTC-3' rev: $5^{\prime}$-AGATGATCTGACCTGCCTGGG-3'

- IL-6 for: 5'-ATTCTGCGCAGCTTTAAGGA-3' rev: 5'-AACAACAATCTGAGGTCGCC-3'

- $\beta$-actin for: 5'-GGACTTCGAGCAAGAGATGG-3' rev: 5'-GATGGAGTTGAAGGTAGTTTCG-3'

\section{Statistical analysis}

The statistical analysis was carried out with the Statistical Package for the Social Sciences (SPSS) 23.0 software (SPSS Inc., Chicago, IL, USA). In case of normal distribution, data were presented as mean $\pm \mathrm{SD}$; one-way analysis of variance (ANOVA), Kruskal Wallis, and Mann-Whitney tests were carried out to compare control and patient groups (both azoospermic and oligozoospermic patients). The coefficients of Spearman's correlation were also determined. Values of $\mathrm{p}<0.05$ were considered statistically significant.

\section{Results}

\section{Semen analysis}

The study population included 45 subjects, of whom 15 had azoospermia, 15 had oligozoospermia and 15 were normozoospermic. All subjects underwent semen analysis.

There were no statistically significant differences among the age of azoospermia and oligozoospermia vs. controls $(37 \pm 5.4 ; 33 \pm 4.8$, and $34 \pm 5.2$ years, respectively $(p>0.24))$. Seminal parameters assessment for the three groups of subjects has been reported in Table 1.

Oligo- and azoospermic patients showed some differences compared to control subjects: the total motility was reduced in oligozoospermic patients $(26.15 \pm 19.27 \%)$ compared to controls $(48 \pm 9.55 \%)(\mathrm{p}=0.02)$, whereas the percentage of the spermatozoa with abnormal forms (AF) and the multiple anomalies indexes (IAM) were higher in oligozoospermic patients than in controls $(90.53 \pm 6.65$ and $81.33 \pm 4.38 \%$ for $\mathrm{AF}, \mathrm{p}=0.01 ; 1.85 \pm 0.27$; $1.58 \pm 0.15 \%$ for IAM, $\mathrm{p}=0.02$ ).

\section{Hormonal and metabolic parameters}

The dosage of LH, prolactin, TG, and $\mathrm{CH}$ showed no significant variation among the three groups. Only FSH and

Table 1 Mean \pm SD for age and semen parameters of the three groups

\begin{tabular}{|c|c|c|c|c|c|c|}
\hline & $\begin{array}{l}\text { Control } \\
(\mathrm{n}=15)\end{array}$ & $\begin{array}{l}\text { Oligozoospermia } \\
(\mathrm{n}=15)\end{array}$ & $\begin{array}{l}\text { Azoospermia } \\
(\mathrm{n}=15)\end{array}$ & p-value ${ }^{1}$ & p-value ${ }^{2}$ & p-value ${ }^{3}$ \\
\hline Age (years) & $34 \pm 5.2$ & $33 \pm 4.8$ & $37 \pm 5.4$ & NS & NS & NS \\
\hline Volume (ml) & $3.3 \pm 1.30$ & $3.86 \pm 1.21$ & $3.39 \pm 0.20$ & NS & NS & NS \\
\hline $\mathrm{pH}$ & $7.8 \pm 0.16$ & $7.94 \pm 0.12$ & $7.95 \pm 0.02$ & NS & NS & NS \\
\hline Concentration $\left(\times 10^{6} \mathrm{spz} / \mathrm{ml}\right)$ & $181.45 \pm 116.8$ & $8.43 \pm 6.4$ & - & $\mathbf{0 . 0 1} *$ & - & - \\
\hline Leucocyte $\left(\times 10^{6} / \mathrm{ml}\right)$ & $0.98 \pm 1.65$ & $0.90 \pm 0.59$ & $0.67 \pm 0.04$ & NS & NS & NS \\
\hline Progressive motility (\%) & $48 \pm 9.55$ & $26.15 \pm 19.27$ & - & $\mathbf{0 . 0 2} *$ & - & - \\
\hline Vitality (\%) & $18.60 \pm 13.62$ & $20.33 \pm 10.26$ & - & NS & - & - \\
\hline Abnormal forms (AF, \%) & $81.33 \pm 4.38$ & $90.53 \pm 6.65$ & - & $\mathbf{0 . 0 1} *$ & - & - \\
\hline Multiple anomalies index (IAM) & $1.58 \pm 0.15$ & $1.85 \pm 0.27$ & - & $\mathbf{0 . 0 2} *$ & - & - \\
\hline
\end{tabular}

Bold values indicate the statistically significant difference

Parametric data was analyzed by Anova test. NS: p-value Not significant; p-value ${ }^{1}$ : control vs. oligozoopermia; p-value ${ }^{2}$ : control vs. azoospermia; $p$-value ${ }^{3}$ : comparison between three groups

*Significant difference $\mathrm{p}<0.05$ 
Table 2 Mean \pm SD of serum hormones between control and study groups

\begin{tabular}{|c|c|c|c|c|c|c|}
\hline & $\begin{array}{l}\text { Control } \\
(\mathrm{n}=15)\end{array}$ & $\begin{array}{l}\text { Oligo- } \\
\text { zoospermia } \\
(\mathrm{n}=15)\end{array}$ & $\begin{array}{l}\text { Azoospermia } \\
(n=15)\end{array}$ & p-value ${ }^{1}$ & p-value ${ }^{2}$ & $\overline{p-\text { value }^{3}}$ \\
\hline $\mathrm{LH}(\mathrm{mU} / \mathrm{ml})$ & $4.51 \pm 1.64$ & $5.69 \pm 3.52$ & $6.31 \pm 5.87$ & NS & NS & NS \\
\hline $\mathrm{FSH}(\mathrm{mU} / \mathrm{ml})$ & $3.51 \pm 1.09$ & $9.82 \pm 9.06$ & $16.80 \pm 12.90$ & NS & 0.01 & $0.02 *$ \\
\hline Estrogen $(\mathrm{ng} / \mathrm{ml})$ & $21.38 \pm 1.09$ & $24.85 \pm 7.59$ & $44.27 \pm 21.25$ & NS & 0.01 & $0.02 *$ \\
\hline Prolactin (pmol/1) & $142.62 \pm 86$ & $163.05 \pm 76$ & $221.20 \pm 103$ & NS & NS & NS \\
\hline Triglycerides (mmol/l) & $4.43 \pm 0.88$ & $3.62 \pm 1.03$ & $4.20 \pm 0.71$ & NS & NS & NS \\
\hline Cholesterol (mmol/l) & $1.09 \pm 0.71$ & $1.23 \pm 0.45$ & $1.74 \pm 1.07$ & NS & NS & NS \\
\hline
\end{tabular}

Bold values indicate the statistically significant difference

Parametric data was analyzed by Anova test. NS: p-value Not significant; p-value ${ }^{1}$ : control vs. oligozoospermia; $\mathrm{p}$-value ${ }^{2}$ : control vs. azoospermia; $\mathrm{p}$-value ${ }^{3}$ : comparison between 3 groups

*Significant difference with control group $(\mathrm{p}<0.05)$ eostrogen were significantly higher $(\mathrm{p}=0.02)$ in azoospermic patients than in controls and oligozoospermics (Table 2).

\section{Expression of inflammatory biomarkers and correlation with semen characteristics and biochemical parameters}

In seminal plasma mRNA of cytokines (TNF- $\alpha$, IL-6), miRNAs (miR-146a-5p; miR-34a-5p; miR-23a-5p) and protein expression of and IL- $1 \alpha$ have been detected, all the data are shown in Table 3.
Among the three cytokines, IL- $1 \alpha$ showed a statistically significant variation in azoospermic group compared to controls $(\mathrm{p}<0.05)$ while TNF- $\alpha$ mRNA was more expressed in the oligozoospermic group compared to controls $(\mathrm{p}<0.05)$. For miRNAs, no significant differences among the three groups were detected (Table 3 ).

The associations between miRNAs and cytokines expression in the three groups (control, oligo- and azoospermic) were checked. For oligozoospermic, only a positive correlation between miR-23a-3p and miR-34a-5p $(r=0.576$; $\mathrm{p}=0.008$ ) compared to controls was found.

Correlations among semen parameters, miRNAs and inflammatory markers were evaluated in oligo- and
Table 3 Mean \pm SD and median (in brackets) of pro-inflammatory cytokines and microRNA in control, oligo- and azoospermic groups analyzed using Anova, Kruskal Wallis and Mann-Whitney test

\begin{tabular}{|c|c|c|c|c|c|c|}
\hline & Control & Oligozoospermia & Azoospermia & p-value ${ }^{1}$ & p-value ${ }^{2}$ & p-value ${ }^{3}$ \\
\hline TNF- $\alpha$ & $\begin{array}{l}0.056 \pm 0.079 \\
(0.021) \\
(\mathrm{n}=10)\end{array}$ & $\begin{array}{l}0.336 \pm 0.567 \\
(0.105) \\
(n=15)\end{array}$ & $\begin{array}{l}0.168 \pm 0.243 \\
(0.067) \\
(\mathrm{n}=11)\end{array}$ & $0.05^{*}$ & NS & NS \\
\hline IL-6 & $\begin{array}{l}0.001 \pm 0.0004 \\
(0.0010) \\
(\mathrm{n}=11)\end{array}$ & $\begin{array}{l}0.018 \pm 0.056 \\
(0.0014) \\
(n=14)\end{array}$ & $\begin{array}{l}0.005 \pm 0.012 \\
(0.0015) \\
(n=10)\end{array}$ & NS & NS & NS \\
\hline MiR-146a-5p & $\begin{array}{l}0.048 \pm 0.06 \\
(0.0218) \\
(n=10)\end{array}$ & $\begin{array}{l}0.059 \pm 0.011 \\
(0.228) \\
(\mathrm{n}=10)\end{array}$ & $\begin{array}{l}0.048 \pm 0.046 \\
(0.041) \\
(\mathrm{n}=10)\end{array}$ & NS & NS & NS \\
\hline MiR-34a-5p & $\begin{array}{l}0.033 \pm 0.055 \\
(0.009) \\
(\mathrm{n}=10)\end{array}$ & $\begin{array}{l}0.015 \pm 0.010 \\
(0.014) \\
(\mathrm{n}=10)\end{array}$ & $\begin{array}{l}0.061 \pm 0.071 \\
(0.032) \\
(\mathrm{n}=10)\end{array}$ & NS & NS & NS \\
\hline MiR-23a-3p & $\begin{array}{l}0.006 \pm 0.011 \\
(0.0012) \\
(n=10)\end{array}$ & $\begin{array}{l}0.0026 \pm 0.0020 \\
(0.0021) \\
(\mathrm{n}=10)\end{array}$ & $\begin{array}{l}0.011 \pm 0.010 \\
(0.012) \\
(\mathrm{n}=10)\end{array}$ & NS & NS & NS \\
\hline IL-1 $\alpha(\mathrm{pg} / \mathrm{ml})$ & $\begin{array}{l}12.43 \pm 8.03 \\
(12.92) \\
(n=14)\end{array}$ & $\begin{array}{l}11.01 \pm 10.64 \\
(4.52) \\
(n=13)\end{array}$ & $\begin{array}{l}23.33 \pm 18.35 \\
(21.16) \\
(\mathrm{n}=13)\end{array}$ & NS & $0.05^{*}$ & $0.05^{*}$ \\
\hline
\end{tabular}

Bold values indicate the statistically significant difference

TNF- $\alpha$, IL-6, miR-0146a-5p, miR-34a-5p and miR-23a-3p are analyzed by Real-Time PCR; IL-1 $\alpha$ analyzed by ELISA

p-value $^{1}$ : control vs. oligozoospermia; -value $^{2}$ : control vs. azoospermia; $p$-value ${ }^{3}$ : comparison between three groups

*Significant difference with control group $(\mathrm{p} \leq 0.05)$ 
azoospermic groups vs. controls. For the oligozoospermic group, positive correlations were found between TNF- $\alpha$ vs. viability $(\mathrm{r}=0.456, \mathrm{p}=0.022)$ and $\mathrm{FSH}(\mathrm{r}=0.476$, $\mathrm{p}=0.025$ ); IL-6 shows a positive correlation vs. the percentage of abnormal form $(r=0.571, p=0.003)$. Levels of $\mathrm{CH}$ correlate negatively with IL- $1 \alpha(\mathrm{r}=-0.485, \mathrm{p}=0.026)$, miR-146a-5p $(r=-0.478, p=0.045)$ and miR-23a-3p $(r$ $=-0.524, p=0.026)$. Comparing azoospermic groups to controls, a negative correlation between IL- 6 vs. TNF- $\alpha(r=$ $-0,496 ; p=0.036$ ) was found; in addition, a positive correlation was noted between IL- $1 \alpha$ and miR-146a-5p $(r=0.513$; $\mathrm{p}=0.025)$ as well as between miR-146a-5p and miR-23a-3p $(r=0.466 ; p=0.044)$. Lastly, a negative correlation between $\mathrm{IL}-1 \alpha$ vs. semen volume $(\mathrm{r}=-0.515, \mathrm{p}=0.006)$ and IL-6 vs. $\mathrm{CH}(\mathrm{r}=-0.567, \mathrm{p}=0.028)$ was found.

\section{Discussion}

In the current research, IL- $1 \alpha$ protein expression, IL- 6 and TNF- $\alpha$ gene expression, and miRNAs expression (miR146a-5p, miR-23a-3p, miR-34a-5p) were evaluated, along with their association with sperm parameters in control, oligo- and azoospermic patients.

Concerning the inflammatory markers, a previous study highlighted that the oligozoospermic group had higher significant concentrations of IL- 6 and the azoospermic group had higher significant concentrations of TNF- $\alpha$ [20]. However, the authors analyzed the protein and not the mRNA expression. The other differences in semen parameters such as motility, abnormal form, and IAM detected between control and oligozoospermic groups, confirm what was previously reported by Agarwal et al. [21].

Higher levels of FSH and estrogen have been detected in azoospermic patients compared to controls. These results are in line with previous researches reporting as an elevated concentration of these hormones correlates with impaired spermatogenesis and fertility [22].

After semen characterization, the expression of cytokines (IL-6, IL- $1 \alpha$, TNF- $\alpha$ ) and miRNAs quantification (miR34a-5p, miR-146a-5p, miR-23a-3p) was evaluated.

Among cytokines, TNF- $\alpha$ was upregulated in oligozoospermic patients vs. controls and azoospermics. TNF- $\alpha$ is the most studied and effective molecule in germ cell apoptosis, peritubular cell secretion, and spermatogenesis control [23]. In Sertoli and Leydig cells are present TNF- $\alpha$ receptors, allowing it to control secretion from these cells [24, 25]. Some studies have shown a negative association of TNF- $\alpha$ plasma levels with sperm motility and morphology $[26,27]$. This upregulation seems to contradict results from Chyra-Jach et al. reporting a down-regulation of about $10 \%$ in the secretion of TNF- $\alpha$ in oligozoospermic vs. control [28]. Nevertheless, they measured the protein amount and not the mRNA expression therefore this apparent discrepancy may imply a post-transcriptional control.

Besides, the expression of TNF- $\alpha$ in the oligozoospermic group correlates with a higher level of FSH but it is not associated with all the other clinically relevant parameters of semen quality, confirming results by Eggert-Kruse et al. [29], although the TNF- $\alpha$ receptor in Sertoli cells is under control by the FSH hormone [24].

IL- $1 \alpha$ secretion was significantly higher in azoospermic patients than in controls and oligozoospermic. IL- $1 \alpha$ is primarily developed by the seminiferous epithelium, where it has been identified as a potent growth factor for immature Sertoli cells as well as spermatogonia in numerous studies [30, 31].

As demonstrated by Buch et al. cytokines such as IL-1 $\alpha$ and TNF- $\alpha$ can lead to sperm damage through the production of ROS and subsequent lipid peroxidation [32, 33].

IL-6 expression was almost the same in the three groups in line with results from Chyra-Jach et al. [28]. The association between IL- 6 cytokine levels and semen quality is still debated, on one hand, elevated levels of IL-6 have been documented in infertile men with oligo-asthenoteratozoospermia, on the other hand, there is no linkage between cytokine levels and sperm quality [33-35]. The expression of miR-146a-5p, miR-34a-5p, miR-23a-3p did not exhibit significant changes between infertile men and controls; nevertheless, in oligozoospermic and in an azoospermic group compared to controls, miR34a-5p positively correlated with miR-23a-5p and since each of them is involved in male infertility, this positive correlation may reflect a synergistic action. It is important to remember that the members of miR-34 family are regulated directly by p53 and their upregulation stimulates the arrest of the cell cycle in stage G1 and induces apoptosis [36].

In the azoospermic group compared to controls, miR$146 a-5 p$ positively correlates with IL- $1 \alpha$ but not with the TNF- $\alpha$ pathway as reported by others previously $[37,38]$. MiR-146a-5p has been shown to have anti-inflammatory properties, in fact it regulates IL-1 receptor-associated kinase (IRAK)-1 and TNF receptor-associated factor (TRAF)-6; these are mediators of the cellular response to IL- $1 \alpha[39,40]$.

As a final point, correlations between inflammatory markers and semen parameters were checked; for oligozoospermic patients compared to controls, IL-6 positively correlates with the percentage of an atypical form of spermatozoa, according to previous results reporting as high IL-6 concentration occurred significantly in case of reduced functional competence of spermatozoa [34]. Interestingly, cholesterol negatively correlates with three inflammatory markers (IL-6, IL-1 $\alpha$, miR-23a-3p); testicular functions such as steroidogenesis, Sertoli cell function, and germ cell differentiation all include cholesterol 
homeostasis [41, 42]. The decrease of cholesterol together with an increase of inflammatory markers may synergically impact the reproductive function leading to male infertility. The same negative correlation between cholesterol and IL-6 was also observed in azoospermic patients; in this group, no particular other correlation was found confirming as cytokine concentrations are not always related to sperm parameters [42-45].

Thus, even though an assay of selective cytokines and microRNAs in the semen can improve the diagnosis of male infertility, measuring each inflammatory marker separately in the seminal plasma of subfertile men has no diagnostic value in male infertility, despite some important differences. In light of the small number of studies that have investigated the relationship between pro-inflammatory cytokines, miRNAs and sperm parameters, ours may represent an intriguing approach. However, to finer comprehend the mechanisms that provide pathways for miRNAs up or downregulation, as well as the function of pro-inflammatory cytokines in seminal plasma and male infertility, further studies with larger numbers of patients are needed.

\section{Conclusions}

In summary, in fertile and infertile patients's seminal plasma, the expression of cytokines (TNF- $\alpha$, IL-6), miRNAs (miR-146a-5p, miR-34a-5p, miR-23a-3p) and IL-1 $\alpha$ protein was not strongly correlated to any standard sperm parameters. Since the seminal fluid is consisting of the different secretions coming from the testis, epididymis, prostate and accessory glands, it is difficult to identify the direct origins of the cytokines and miRNAs analyzed. Cytokines work within a network that can be influenced by various factors, therefore the levels of expression observed in the study may have been influenced by poor selection and processing of the samples as well as by their molecular instability. Hence, proinflammatory cytokines appear neither to play an essential role in male infertility nor to contribute to oligospermia and azoospermia. Cytokines may activate inflammation directly or indirectly in the presence of other molecules such as miRNAs, hormones, lipidic molecules. More research in seminal plasma is needed to improve our knowledge about the key role of pro-inflammatory cytokines and microRNAs. It is also important to underline that the analysis of the expression of the IL- $1 \alpha$ protein provides different information compared to the analysis of the mRNA expression of the other two cytokines, therefore it will be important to also evaluate the protein expression of the other molecules.

The investigation of the relationships between proinflammatory cytokines, specific miRNAs, and biochemical molecules in seminal plasma may give new insights about inflammation and/or dysfunction of spermatogenesis in hypo-fertile patients.

Author contributions HA conceived and designed the experiments; MM \& IZJ patients enrollements; RL and HA acquired and analysed the data; HA and FF wrote the article; HA and MO data interpretation; GB and MMB contributed to manuscript revision. All authors approved the final version of the manuscript.

Funding Open access funding provided by Università Politecnica delle Marche within the CRUI-CARE Agreement. This research did not receive any specific grant from funding agencies in the public, commercial, or not-for-profit sectors.

\section{Declarations}

Conflict of interest The authors declare that there are no conflicts of interest.

Open Access This article is licensed under a Creative Commons Attribution 4.0 International License, which permits use, sharing, adaptation, distribution and reproduction in any medium or format, as long as you give appropriate credit to the original author(s) and the source, provide a link to the Creative Commons licence, and indicate if changes were made. The images or other third party material in this article are included in the article's Creative Commons licence, unless indicated otherwise in a credit line to the material. If material is not included in the article's Creative Commons licence and your intended use is not permitted by statutory regulation or exceeds the permitted use, you will need to obtain permission directly from the copyright holder. To view a copy of this licence, visit http://creativecommons.org/licenses/by/4.0/.

\section{References}

1. Tronchon V, Vialard F, El Sirkasi M, Dechaud H, Rollet J, Albert M, Bailly M, Roy P, Mauduit C, Fenichel P, Selva J, Benahmed M (2008) Tumor necrosis factor-alpha-308 polymorphism in infertile men with altered sperm production or motility. Hum Reprod 23:2858-2866. https://doi.org/10.1093/humrep/den277

2. Petersen C, Froysa B, Soder O (2004) Endotoxin and proinflammatory cytokines modulate Sertoli cell proliferation in vitro. J Reprod Immunol 61:13-30. https://doi.org/10.1016/j.jri.2003.10. 003

3. Comhaire F, Bosmans E, Ombelet W, Punjabi U, Schoonjans F (1994) Cytokines in semen of normal men and of patients with andrological diseases. Am J Reprod Immunol 31:99-103. https:// doi.org/10.1111/j.1600-0897.1994.tb00853.x

4. Ochsendorf FR (1999) Infections in the male genital tract and reactive oxygen species. Hum Reprod Update 5(5):399-420. https://doi.org/10.1093/humupd/5.5.399

5. O'Bryan MK, Hedger MP (2008) Inflammatory networks in the control of spermatogenesis. Chronic inflammation in an immunologically privileged tissue? Adv Exp Med Biol 636:92-114. https://doi.org/10.1007/978-0-387-09597-4_6

6. Hajeer AH, Hutchinson IV (2001) Influence of TNF gene polymorphisms on TNF production and disease. Hum Immunol 62:1191-1199. https://doi.org/10.1016/s0198-8859(01)00322-6

7. Said TM, Agarwal A, Falcone T, Sharma RK, Bedaiwy MA, Li L (2005) Infliximab may reverse the toxic effects induced by tumor necrosis factor alpha in human spermatozoa: an in vitro model. 
Fertil Steril 83(6):1665-1673. https://doi.org/10.1016/j.fertnstert. 2004.11.068

8. Shukla KK, Chambial S, Dwivedi S, Misra S, Sharma P (2014) Recent scenario of obesity and male fertility. Andrology 2:809818. https://doi.org/10.1111/andr.270

9. Dousset B, Hussenet F, Daudin M, Bujan L, Foliguet B, Nabet P (1997) Seminal cytokine concentrations (IL-1beta, IL-2, IL-6, sR IL-2, sR IL-6), semen parameters and blood hormonal status in male infertility. Hum Reprod 12:1476-1479. https://doi.org/10. 1093/humrep/12.7.1476

10. Loveland KL, Klein B, Pueschl D, Indumathy S, Bergmann M, Loveland BE, Hedger MP, Schuppe HC (2017) Cytokines in male fertility and reproductive pathologies: immunoregulation and beyond. Front Endocrinol (Lausanne) 8:307. https://doi.org/10. 3389/fendo.2017.00307

11. Khawar MB, Mehmood R, Roohi N (2019) MicroRNAs: recent insights towards their role in male infertility and reproductive cancers. Bosn J Basic Med Sci 19:31-42. https://doi.org/10.17305/ bjbms.2018.3477

12. Huszar JM, Payne CJ (2013) MicroRNA 146 (Mir146) modulates spermatogonial differentiation by retinoic acid in mice. Biol Reprod 88:15. https://doi.org/10.1095/biolreprod.112.103747

13. Abu-Halima M, Ayesh BM, Hart M, Alles J, Fischer U, Hammadeh M, Keller A, Huleihel M, Meese E (2019) Differential expression of miR-23a/b-3p and its target genes in male patients with subfertility. Fertil Steril 112(2):323-335.e2. https://doi.org/ 10.1016/j.fertnstert.2019.03.025

14. Balasubramanian A, Thirumavalavan N, Pastuszak AW (2019) Evolving insights into the relationship between miR-23a/b-3p and target genes in subfertile patients. Fertil Steril 112(2):241242. https://doi.org/10.1016/j.fertnstert.2019.04.036

15. WHO (2010) WHO laboratory manual for the examination and processing of human semen, 5th edn. World Health Organization, Geneva

16. Auger J, Eustache F, David G (2000) Standardization of the morphological classification of human spermatozoa according to the modified David method. Andrologie 10:358-373. https:// doi.org/10.1007/BF03034491

17. Olivieri F, Lazzarini R, Recchioni R, Marcheselli F, Rippo MR, Di Nuzzo S, Albertini MC, Graciotti L, Babini L, Mariotti S, Spada G, Abbatecola AM, Antonicelli R, Franceschi C, Procopio AD (2013) MiR-146a as marker of senescence-associated pro-inflammatory status in cells involved in vascular remodelling. Age (Dordr) 35:1157-1172. https://doi.org/10.1007/ s11357-012-9440-8

18. Lazzarini R, Olivieri F, Ferretti C, Mattioli-Belmonte M, Di Primio R, Orciani M (2014) mRNAs and miRNAs profiling of mesenchymal stem cells derived from amniotic fluid and skin: the double face of the coin. Cell Tissue Res 355(1):121-130. https://doi.org/10.1007/s00441-013-1725-4

19. Finocchi F, Pelloni M, Balercia G, Pallotti F, Radicioni AF, Lenzi A, Lombardo F, Paoli D (2020) Seminal plasma miRNAs in Klinefelter syndrome and in obstructive and nonobstructive azoospermia. Mol Biol Rep 47(6):4373-4382. https://doi.org/ 10.1007/s11033-020-05552-x

20. Seshadri S, Bates M, Vince G, Jones DIL (2009) The role of cytokine expression in different subgroups of subfertile men. Am J Reprod Immunol 62(5):275-282. https://doi.org/10. 1111/j.1600-0897.2009.00736.x

21. Agarwal A, Mulgund A, Sharma R, Sabanegh E (2014) Mechanisms of oligozoospermia: an oxidative stress perspective. Syst Biol Reprod Med 60:206-216. https://doi.org/10.3109/19396 368.2014.918675

22. Matthiesson KL, McLachlan RI, O’Donnell L, Frydenberg M, Robertson DM, Stanton PG, Meachem SJ (2006) The relative roles of follicle-stimulating hormone and luteinizing hormone in maintaining spermatogonial maturation and spermiation in normal men. J Clin Endocrinol Metab 91:3962-3969. https:// doi.org/10.1210/jc.2006-1145

23. Siciliano L, Tarantino P, Longobardi F, Rago V, De Stefano C, Carpino A (2001) Impaired seminal antioxidant capacity in human semen with hyperviscosity or oligo-asthenozoospermia. J Androl 22:798-803. https://doi.org/10.1002/j.1939-4640. 2001.tb02583

24. Mauduit C, Besset V, Caussanel V, Benahmed M (1996) Tumor necrosis factor alpha receptor p55 is under hormonal (folliclestimulating hormone) control in testicular Sertoli cells. Biochem Biophys Res Commun 224:631-637. https://doi.org/10.1006/bbrc. 1996.1077

25. Bami MK, Tezerjani MD, Montazeri F, Ashrafzadeh Mehrjardi HR, Ghasemi-Esmailabad S, Sheikhha MH, Kalantar SM (2017) Tumor necrosis factor alpha-308 G/A single nucleotide polymorphism and risk of sperm abnormalities in Iranian males. Int $\mathbf{J}$ Fertil Steril 11:112-116. https://doi.org/10.22074/ijfs.2017.4830

26. Eisermann J, Register KB, Strickler RC, Collins JL (1989) The effect of tumor necrosis factor on human sperm motility in vitro. J Androl 10(4):270-274. https://doi.org/10.1002/j.1939-4640.1989. tb00100.x

27. Koçak I, Yenisey C, Dündar M, Okyay P, Serter M (2002) Relationship between seminal plasma interleukin- 6 and tumor necrosis factor alpha levels with semen parameters in fertile and infertile men. Urol Res 30(4):263-267. https://doi.org/10.1007/ s00240-002-0269-y

28. Chyra-Jach D, Kaletka Z, Dobrakowski M, Machoń-Grecka A, Kasperczyk S, Birkner E, Kasperczyk A (2018) The associations between infertility and antioxidants, proinflammatory cytokines, and chemokines. Oxid Med Cell Longev. https://doi.org/10.1155/ 2018/8354747

29. Eggert-Kruse W, Boit R, Rohr G, Aufenanger J, Hund M. Strowitzki T (2001) Relationship of seminal plasma interleukin (IL)-8 and IL-6 with semen quality. Hum Reprod 16:517-528. https:// doi.org/10.1093/humrep/16.3.517

30. Huleihel M, Lunenfeld E, Horowitz S, Levy A, Potashnik G, Glezerman M (2000) Production of interleukin-1-like molecules by human sperm cells. Fertil Steril 73:1132-1137. https://doi.org/ 10.1016/s0015-0282(00)00499-4

31. Rozwadowska N, Fiszer D, Jedrzejczak P, Kosicki W, Kurpisz $M$ (2007) Interleukin-1 superfamily genes expression in normal or impaired human spermatogenesis. Genes Immun 8:100-107. https://doi.org/10.1038/sj.gene.6364356

32. Buch JP, Kolon T, Maulik N, Kreutzer D, Das DK (1994) Cytokines stimulate lipid membrane peroxidation of human sperm. Fertil Steril 62:186-188. https://doi.org/10.1016/s00150282(16)56838-1

33. Nabil H, Moamen L (2008) Increased tumor necrosis factor alpha and interleukin-18 levels in seminal plasma of infertile males. Res J Med Sci 3:115-117

34. Matalliotakis I, Arici A, Goumenou A, Koumantakis G, Selam B, Matalliotakis G, Koumantakis E (2002) Distinct expression pattern of cytokines in semen of men with genital infection and oligoterato-asthenozoospermia. Am J Reprod Immunol 48:170-175. https://doi.org/10.1034/j.1600-0897.2002.01086.x

35. Friebe K, Bohring C, Skrzypek J, Krause W (2003) Levels of interleukin-6 and interleukin-8 in seminal fluid of men attending an andrological clinic. Andrologia 35:126-129. https://doi.org/ 10.1046/j.1439-0272.2003.00544.x

36. Hermeking H (2009) The miR-34 family in cancer and apoptosis. Cell Death Differ 17:193-199. https://doi.org/10.1038/cdd.2009. 56

37. Fraczek M, Kurpisz M (2015) Cytokines in the male reproductive tract and their role in infertility disorders. J Reprod Immunol 108:98-104. https://doi.org/10.1016/j.jri.2015.02.001 
38. Taganov KD, Boldin MP, Chang KJ, Baltimore D (2006) NFkappa B-dependent induction of microRNA miR 146, an inhibitor targeted to signaling proteins of innate immune responses. Proc Natl Acad Sci 103:12481-12486. https://doi.org/10.1073/pnas. 0605298103

39. Jiang P, Liu R, Zheng Y, Liu X, Chang L, Xiong S, Chu Y (2012) MiR-34a inhibits lipopolysaccharide-induced inflammatory response through targeting Notch1 in murine macrophages. Exp Cell Res 318:1175-1184. https://doi.org/10.1016/j.yexcr.2012.03. 018

40. Eggert-Kruse W, Kiefer I, Beck C, Demirakca T, Strowitzki T (2007) Role for tumor necrosis factor alpha (TNF-alpha) and interleukin 1-beta (IL-1beta) determination in seminal plasma during infertility investigation. Fertil Steril 87:810-823. https://doi.org/ 10.1016/j.fertnstert.2006.08.103

41. Jiang W, Kong L, Ni Q, Lu Y, Ding W, Liu G, Pu L, Tang W, Kong L (2014) miR-146a ameliorates liver ischemia/reperfusion injury by suppressing IRAK1 and TRAF6. PLoS One 9:e101530. https://doi.org/10.1371/journal.pone.0101530

42. Michell DL, Vickers KC (2016) HDL and microRNA therapeutics in cardiovascular disease. Pharmacol Ther 168:43-52. https://doi. org/10.1016/j.pharmthera.2016.09.001
43. Abu-Halima M, Ludwig N, Hart M, Leidinger P, Backes C, Keller A, Hammadeh M, Meese E (2016) Altered micro-ribonucleic acid expression profiles of extracellular microvesicles in the seminal plasma of patients with oligoasthenozoospermia. Fertil Steril 106(5):1061. https://doi.org/10.1016/j.fertnstert.2016.06.030

44. Papadimas J, Goulis DG, Sotiriades A, Daniilidis M, Fleva A, Bontis JN, Tourkantonis A (2002) Interleukin-1 beta and tumor necrosis factor-alpha in normal/infertile men. Arch Androl 48:107-113. https://doi.org/10.1080/014850102317267418

45. Sèdes L, Thirouard L, Maqdasy S, Garcia M, Caira F, Lobaccaro JA, Beaudoin C, Volle DH (2018) Cholesterol: a gatekeeper of male fertility? Front Endocrinol (Lausanne) 9:369. https://doi.org/ 10.3389/fendo.2018.00369

Publisher's Note Springer Nature remains neutral with regard to jurisdictional claims in published maps and institutional affiliations. 